\title{
Bioefficiency of different tocopherols in chicken as assessed by haemolysis test and microsomal pentane production
}

\author{
BY HERBERT FUHRMANN, SUKURANI T. BALTHAZARY \\ AND HANS-PETER SALLMAN N* \\ Department of Physiological Chemistry, Hanover Veterinary School, Buenteweg 17, \\ 30559 Hannover 71, Germany
}

(Received 20 August 1992 - Revised 15 June 1993 - Accepted 8 July 1993)

\begin{abstract}
Bioefficiencies of $\alpha$-, $\gamma$ - and $\delta$-tocopherol in comparison with all-rac- $\alpha$-tocopherol were established in broiler chickens. For this, 1-d-old male broiler chickens received a diet deficient in vitamin $E$ and supplemented with increasing doses of the corresponding tocopheryl acetates. After 2 and 3 weeks of feeding, the animals were killed to obtain blood and liver samples. The ex vivo tests used were detergentinduced haemolysis and pentane production by liver microsomes. Bioefficiencies were calculated by comparison of the dose-response curves. It is concluded that haemolysis and pentane production are appropriate indicators of the bioefficiency of tocopherols in broiler chickens. The values obtained by both tests hardly differed and agree well with the figures previously obtained from rats and other species.
\end{abstract}

Bioefficiency: Vitamin E: Pentane: Haemolysis: Chicken

Plant oils are rich sources of tocopherols. However, the distribution of these tocopherols is uneven; D- $\gamma$-tocopherol (D- $\gamma-\mathrm{T})$ and $\mathrm{D}-\delta$-tocopherol $(\mathrm{D}-\delta$-T) are found in substantial amounts. Due to the widespread use of vegetable oils, especially soya-bean oil, in human and animal nutrition, $\mathrm{D}-\gamma-\mathrm{T}$ and $\mathrm{D}-\delta$-T have become important tocopherols in food and feed. In spite of this, it has been customary to assess vitamin E bioactivity of diets and feeds solely on RRR- $\alpha$-tocopherol (RRR- $\alpha$-T). The abundance of the non- $\alpha$-tocopherols in natural feeds raised the question of whether $\mathrm{D}-\gamma-\mathrm{T}$ and $\mathrm{D}-\delta-\mathrm{T}$ make a significant contribution to the total tocopherol bioactivity in food and feed.

In poultry farming, tocopherols are incorporated in the feed as additives. The basis for such supplementation should be a thorough knowledge on the bioefficiencies of these vitamins. However, the information available on biopotency of the different tocopherols in chickens is limited (Bieri \& Poukka, 1974b). For these reasons an attempt was made to reassess the bioefficiencies of three naturally occurring tocopherols relative to all-rac- $\alpha$ tocopheryl acetate (all-rac- $\alpha$-TA) as the reference substance for broiler chicken in a feeding experiment. The tests employed were haemolysis, and pentane production from liver microsomes.

The haemolysis test is based on the measurement of the resistance of erythrocyte cell membranes against stress imposed by $\mathrm{H}_{2} \mathrm{O}_{2}$, dialuric acid or polyoxyethylene sorbitan monolaurate (Tween 20). The method was first developed by Rose \& György (1952) and modified by Friedman et al. (1958), Draper \& Csallany (1969) and Hamada \& Matsumoto (1980). The test is applicable in vitro as well as ex vivo. For the latter the tocopherol is fed to or injected into the animal and the test is performed on isolated erythrocytes.

Ethane and pentane are produced as secondary products during cellular lipid 
peroxidation (Hafemann \& Hoekstra, 1977). While ethane originates from the corresponding $n-3$ fatty acids, pentane stems from the $n-6$ fatty acids, mainly arachidonic acid. Until now microsomal pentane production, induced by ADP-Fe, has not been used for estimation of the bioefficiency of different tocopherols.

\section{MATERIALS AND METHODS}

Two consecutive experiments with growing broiler chickens receiving different types and dosages of tocopherols in their feed were conducted. For both experiments all-rac- $\alpha$-TA was used as the standard tocopherol, because it is the tocopherol widely used as a feed additive and in pharmacological preparations. In the first experiment ten groups of chickens received increasing concentrations of all-rac- $\alpha$-TA and $D-\gamma$-tocopheryl acetate (D- $\gamma$-TA); in the second experiment seventeen groups received increasing amounts of allrac- $\alpha$-TA, RRR- $\alpha$-tocopheryl acetate (RRR- $\alpha$-TA) and D- $\delta$-TA (Table 1).

Male broiler chickens (1-d-old; Arbor Acres, Hattem, The Netherlands) were randomly divided into groups consisting of fourteen to sixteen animals. Each group was housed in a wire cage. The environment in the fully air-conditioned room was kept constant for both experiments by maintaining the temperature at $32( \pm 1)^{\circ}$ during the first week and making weekly reductions of $2-3^{\circ}$ until $25^{\circ}$ was reached. Humidity was maintained at $60 \pm 5 \%$. Light was provided for $24 \mathrm{~h}$.

The feed (Table 2) consisted of a tocopherol-deficient basal diet and $100 \mathrm{~g}$ fat $/ \mathrm{kg}$. The basal diet was prepared as one batch for both experiments. The fat used was a re-esterified triacylglycerol made from soya-bean oil, containing ( $\mathrm{g} / 100 \mathrm{~g}$ total fatty acids) $18: 1,24$; $18: 2,49$ and $18: 3,6$. The different tocopherols were mixed with the fat before the addition of this component to the basal feed. Tocopherol content of the vitamin E-deficient diet was $\leqslant 0.1 \mathrm{mg}$ RRR- $\alpha-\mathrm{T}, 0.4 \mathrm{mg} \gamma-\mathrm{T}$ and $0.3 \mathrm{mg} \delta-\mathrm{T}$ per $\mathrm{kg}$. The purity of the natural tocopheryl acetates used is shown in Table 3 . The feed was stored in the dark at $-22^{\circ}$.

After 2 weeks, half the birds were randomly selected for examination, 1 week later the other half were examined. The birds were fasted for $18 \mathrm{~h}$ before they were anaesthetized by intramuscular injection of $7.5 \mathrm{mg}$ Metomidat- $\mathrm{HCl}$ (Hypnodil; Janssen, Neuss, Germany) $/ \mathrm{kg}$ body weight. Blood $(5 \mathrm{ml})$ was obtained by cardiac puncture using a heparinized syringe and kept in ice-cold heparinized plastic tubes. Thereupon the birds were killed and completely bled. The liver was homogenized in ice-cold $5 \mathrm{~mm}$-TRIS-maleate buffer $(\mathrm{pH} \mathrm{7.4)}$. The large cellular particles of the liver homogenate were separated by centrifugation at $1400 \mathrm{~g}$ for $10 \mathrm{~min}$ at $4^{\circ}$. The supernatant was removed and centrifuged again at $25000 \mathrm{~g}$ for $45 \mathrm{~min}$ at $4^{\circ}$ for separation of the mitochondria. To obtain the microsomal pellet the supernatant was centrifuged at $104000 \mathrm{~g}$ for $60 \mathrm{~min}$ at $4^{\circ}$. The microsomal pellet was resuspended in $5 \mathrm{~mm}$-TRIS-maleate buffer and used for determination of pentane production and protein (Lowry et al. 1951).

For the haemolysis test (Hamada \& Matsumoto, 1980), $100 \mu$ l blood were pipetted into a plastic test-tube containing $2.5 \mathrm{ml}$ sodium phosphate buffer ( $\mathrm{SPB} ; 76 \mathrm{~mm}-\mathrm{NaCl}, 50 \mathrm{~mm}-$ $\mathrm{Na}_{2} \mathrm{HPO}_{4}, 0.25$ mm-EDTA, $\mathrm{pH} 7.4$ ). The test-tube was sealed and inverted twice to mix the contents. The suspension was centrifuged at $1000 \mathrm{~g}$ for $10 \mathrm{~min}$, and the supernatant discarded. The cell pellet was resuspended in $2.5 \mathrm{ml} \mathrm{SPB}$ by inverting the test-tube gently six times. A $0.5 \mathrm{ml}$ portion of the suspension was pipetted into plastic tubes 1 and 2 . To plastic tubes 3 and $4,0.5 \mathrm{ml} \mathrm{SPB}$ was added. To each tube, $0.5 \mathrm{ml}$ Tween $20(15 \mathrm{~g} / 1$ $0.153 \mathrm{M}-\mathrm{NaCl}$ ) was given, incubated for $15 \mathrm{~min}$ at $37^{\circ}$ and thereafter kept at room temperature for $2 \mathrm{~min}$. To test-tubes 1 and 3,2.5 $\mathrm{ml} \mathrm{SPB}$ and to test-tubes 2 and $4,2.5 \mathrm{ml}$ distilled water was added and the tubes were allowed to stand at room temperature for $3 \mathrm{~min}$. The suspensions were centrifuged at $1000 \mathrm{~g}$ for $10 \mathrm{~min}$. The absorbance of the 
Table 1. Doses of tocopheryl acetates $(\mathrm{mg} / \mathrm{kg}$ feed) used for haemolysis $(H)$ and pentane (P) tests*

(Doses not used for the parallel-line assay are given in parentheses)

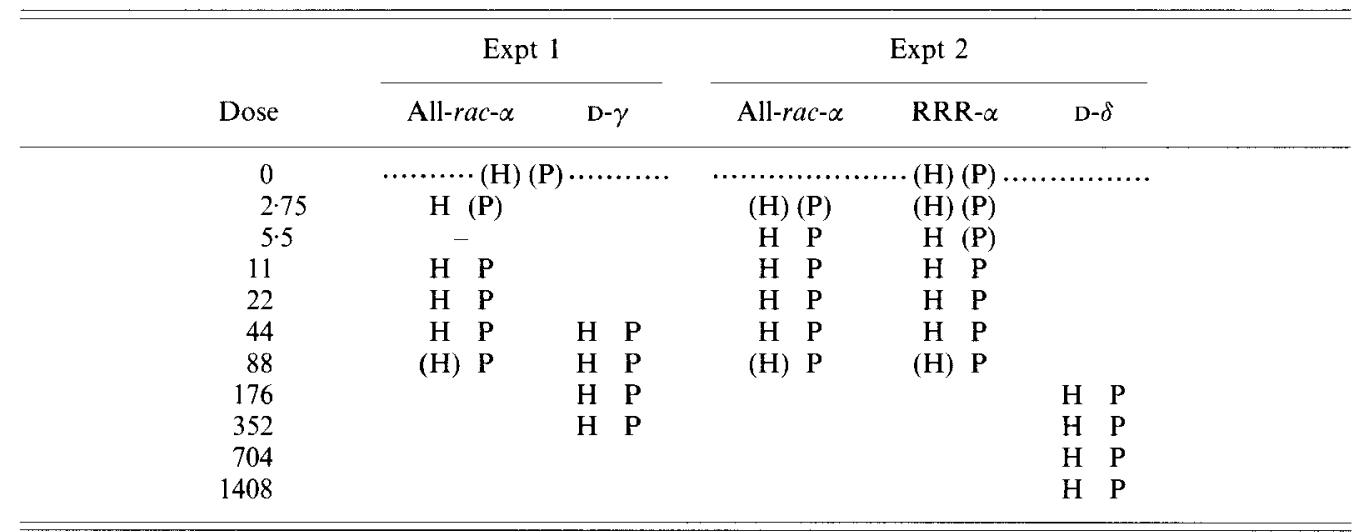

* For details of diets and procedures, see Table 2 and pp. 606-609.

Table 2. Composition of the diet

\begin{tabular}{lr}
\hline \hline Feed ingredient & $\mathrm{g} / \mathrm{kg}$ \\
\hline Glucose & $471 \cdot 3$ \\
Soya-bean protein concentrate & $310 \cdot 0$ \\
Cellulose & $40 \cdot 0$ \\
Methionine & $4 \cdot 0$ \\
Choline chloride & $3 \cdot 2$ \\
Mineral mixture* & $69 \cdot 5$ \\
Vitamin pre-mixture $\dagger$ & $2 \cdot 0$ \\
Re-esterified soya-bean triacyglycerol & $100 \cdot 0$ \\
\hline
\end{tabular}

* The mineral mixture contained (mg per kg final feed): $\mathrm{CaHPO}_{4} \cdot 2 \mathrm{H}_{2} \mathrm{O} 19 \cdot 6, \mathrm{CaCO}_{3} 20 \cdot 5, \mathrm{KH}_{2} \mathrm{PO}_{4} 15 \cdot 2$, $\mathrm{NaHCO}_{3} 9 \cdot 6, \mathrm{MnSO}_{4} . \mathrm{H}_{2} \mathrm{O} 0 \cdot 38, \mathrm{FeSO}_{4} .7 \mathrm{H}_{2} \mathrm{O} 0 \cdot 54, \mathrm{MgSO}_{4} 3 \cdot 28, \mathrm{KIO}_{3} 0 \cdot 01, \mathrm{CuSO}_{4} .5 \mathrm{H}_{2} \mathrm{O} 0 \cdot 036, \mathrm{ZnCO}_{3} 0 \cdot 16$, $\mathrm{CoCl}_{2} 0 \cdot 0034, \mathrm{NaMoO}_{4} \cdot \mathrm{H}_{2} \mathrm{O} 0 \cdot 009, \mathrm{NiCl}_{2} .6 \mathrm{H}_{2} \mathrm{O} 0 \cdot 13, \mathrm{Na}_{2} \mathrm{SeO}_{3} .5 \mathrm{H}_{2} \mathrm{O} 0.000333$.

$\dagger$ Rovimix 428 without vitamin E (a gift of Hoffmann-La Roche, Basle).

Table 3. Composition of the tocopheryl acetates

\begin{tabular}{lrrrr}
\hline \hline & \multicolumn{3}{c}{ Tocopherol (\%) } \\
\cline { 2 - 5 } $\begin{array}{l}\text { Tocopheryl } \\
\text { acetate }\end{array}$ & RRR- $\alpha$ & D- $\gamma$ & D- $\delta$ \\
\hline RRR- $\alpha$-TA & 96.9 & None & None \\
D- $\gamma$-TA & $<0.1$ & 92.0 & $<0.1$ \\
D- $\delta$-TA & 1.6 & 2.5 & 96.6 \\
\hline
\end{tabular}




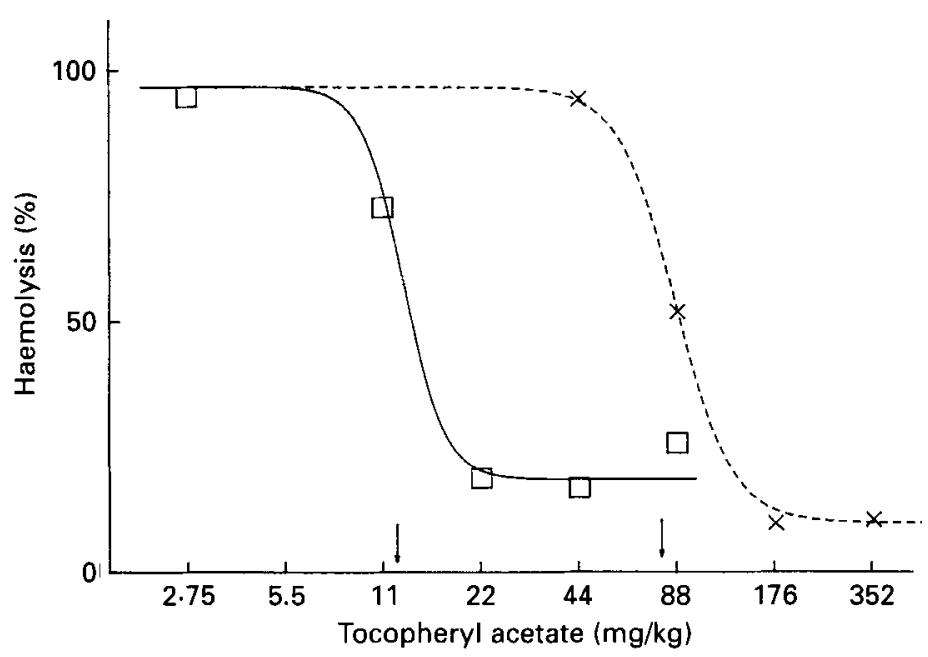

Fig. 1. Haemolysis $(\%)$ and $\operatorname{ED}_{50}(\downarrow)$ after 2 weeks of feeding all-rac- $\alpha$-TA $(\square)$ and D- $\gamma$-TA $(\times)$. Each point represents the mean of six to seven chicks.

supernatant from each test-tube was measured in a photometer at $546 \mathrm{~nm}$. The percentage haemolysis was calculated by using the formula:

$$
\% \text { haemolysis }=\frac{\text { extinction (tube 1) }- \text { extinction (tube } 3)}{\text { extinction (tube } 2)- \text { extinction (tube 4) }} \times 100 .
$$

The amount of pentane produced by liver cell microsomes following provocation with NADPH and iron (Tien \& Aust, 1982) was determined by a headspace technique using a gas chromatograph (Sallmann et al. 1991). The pipetting scheme is given below.

$0.5 \mathrm{ml}$ buffer (100 mM-TRIS-maleate, $0.15 \mathrm{~mm}-\mathrm{KCl})$

$0.1 \mathrm{ml}$ ADP-Fe solution (32.8 $\mathrm{mm}-\mathrm{ADP}, 1.64 \mathrm{mM}^{-\mathrm{FeCl}_{3}}$ )

$0.1 \mathrm{ml} \quad \mathrm{NADPH}+\mathrm{H}^{+}(1.22 \mathrm{~mm}-\mathrm{NADPH})$

$0.5 \mathrm{ml}$ sample in buffer ( $5 \mathrm{mM}$-TRIS-maleate)

\section{$1.2 \mathrm{ml}$ total reaction mixture $(\mathrm{pH} 7 \cdot 4)$}

The reagent vials were placed in a shaking water bath at $37^{\circ}$ and incubated for $30 \mathrm{~min}$. At the end of the reaction time a $1 \mathrm{ml}$ sample of the headspace was aspirated through the septum and immediately analysed by gas chromatography.

For calculation of the biopotency of the tocopherols the parallel-line assay (Pharm/PCS software version 4.2; Tallarida \& Murray, 1987) was adopted. The procedure requires the same number of doses tested for each tocopherol. Therefore four doses from the range of all-rac- $\alpha$-TA and RRR- $\alpha$-TA dosages (only four doses for $\gamma$ - and $\delta$-TA) had to be selected. Calculations were made with all observations (i.e. the number of animals) for each of the four doses chosen. This procedure does not change variances when the lines are fitted.

First it was necessary to explore the dose-response characteristics of the system over a broad range to determine in which part a straight-line relationship existed. The graphs for pentane were logarithmic and could be linearized over the full range of doses by plotting the pentane production $\mathrm{v}$. the log of feed tocopherol. Using the same procedure for haemolysis the curves were sigmoidal and could not be linearized over the full range even by other transformations $(\log / \log$, probit/log). Only percentage haemolysis $\mathrm{v}$. the $\log$ of feed tocopherol gave reasonable results. To confirm this a different approach was employed 
including the full range of haemolysis data. Sigmoidal curves were fitted to the group means by nonlinear regression (GraphPAD version 2.0, 1987; ISI Software, Philadelphia, PA, USA) for calculation of the effective dose for $50 \%$ reduction of haemolysis $\left(E_{50}\right)$ and estimation of the relative biopotency for each tocopherol (Fig. 1).

Using the tocopherol doses shown in Table 1 allowed the tocopherols of unknown bioefficiency to be assayed by the standard curve interpolation method. First it was necessary to know whether the lines obtained by the linear regression were parallel. The procedure compares the slopes of the regression lines by using the Student's $t$ test. If the computed $t$ value was less than the tabulated $t$ value the slopes did not differ significantly and the hypothesis of parallelism was accepted. Because situations were encountered in which the two lines determined by the linear regressions were statistically parallel but nevertheless had slightly different slopes it was necessary to calculate a common slope on the weighted mean of the two slopes. From the common slope the equations for the parallel lines were obtained. Residual variance for calculation of the confidence limits was derived from the variation between birds within a dose group.

\section{RESULTS AND DISCUSSION}

Body weight gain and feed conversion were not different between the two experiments (results not shown) and therefore did not indicate any environmental or feeding effects. This was ensured by using identical environmental conditions in the fully climatized room available and by preparing the basal diet with ingredients from the same batches. Effects like genetic differences between the animals used in the two experiments were avoided by using genetically homogeneous broilers from a commercial breeder. Any other possible bias was ruled out by taking all-rac- $\alpha$-TA as the standard and reference substance in each experiment.

Encephalomalacia was evident only in the groups which received the tocopherol deficient diet, $2.75 \mathrm{mg}$ all-rac- $\alpha$-TA and $2.75 \mathrm{mg}$ RRR- $\alpha$-TA. There was no disease incidence in the groups which received either $\mathrm{D}-\gamma$-TA or D- $\delta$-TA, probably because of the presence of small amounts of RRR- $\alpha$-TA in these tocopherols.

Both the pentane and the haemolysis methods represent functional tests which appear to give valid information on tocopherol efficiencies. The advantage of the animal model applied is that 1-d-old chickens show rapid growth and high turnover rates of tocopherol. The duration of the experiment is therefore shorter than when older, slow-growing birds are used. Several studies have shown that pentane and ethane are good indicators of proneness to endogenous lipid peroxidation (Herschberger \& Tappel, 1982; Gavino et al. 1984). The method of pentane production applied in the present study was developed as an in vitro test by Tien \& Aust (1982) and adopted in chickens by Sallmann et al. (1991). The liver was the source of the microsomes used because it is a major store of tocopherols. It is also the centre of major metabolic processes and has high metabolic turnover rates. The fat incorporated in the basal feed with only traces of natural tocopherols has a considerable proportion of linoleic acid. These are the prerequisites for a microsomal environment appropriate to tocopherol bioefficiency studies. The hydrocarbon pentane was chosen as the substance monitored because under these feeding conditions it is produced in larger amounts than other hydrocarbons.

Pentane production by liver microsomes was influenced by increasing dosages of RRR$\alpha$-TA, D- $\gamma$-TA, D- $\delta$-TA, and all-rac- $\alpha$-TA at both ages examined (Figs. 2 and 3 , data for 3 weeks not shown). The relationship was logarithmic. Comparatively, RRR- $\alpha$-TA appeared to be more effective than all-rac- $\alpha$-TA at equivalent dosages, although this was not statistically significant. The other tocopherols, D- $\gamma$-TA and D- $\delta$-TA were less effective 


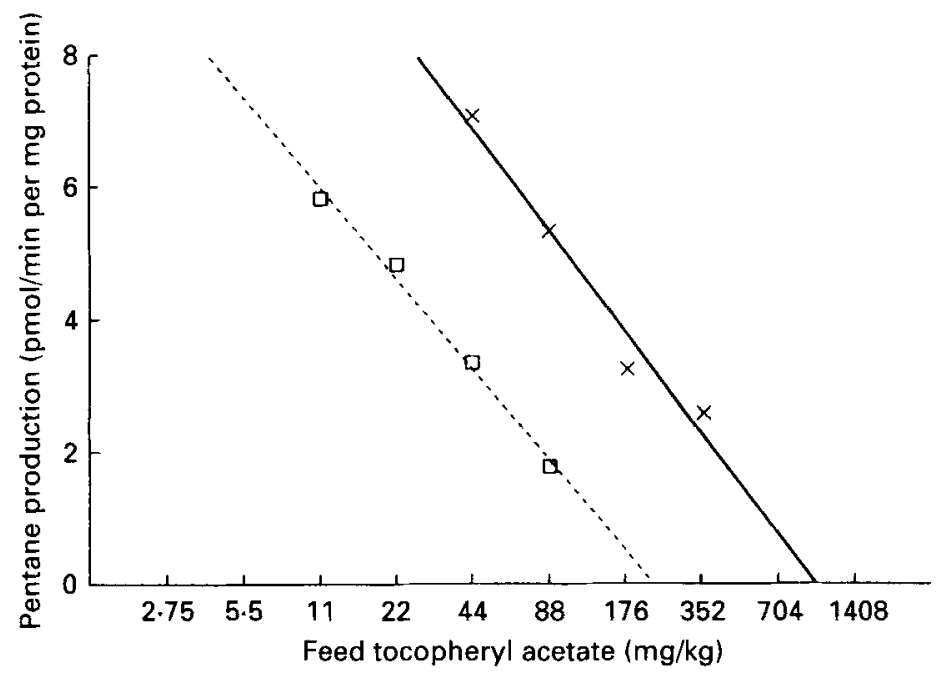

Fig. 2. Pentane production by liver microsomes after 2 weeks of feeding all-rac- $\alpha$-TA $(\square)$ and D- $\gamma$-TA $(\times)$. Each point represents the mean of six to seven chicks.

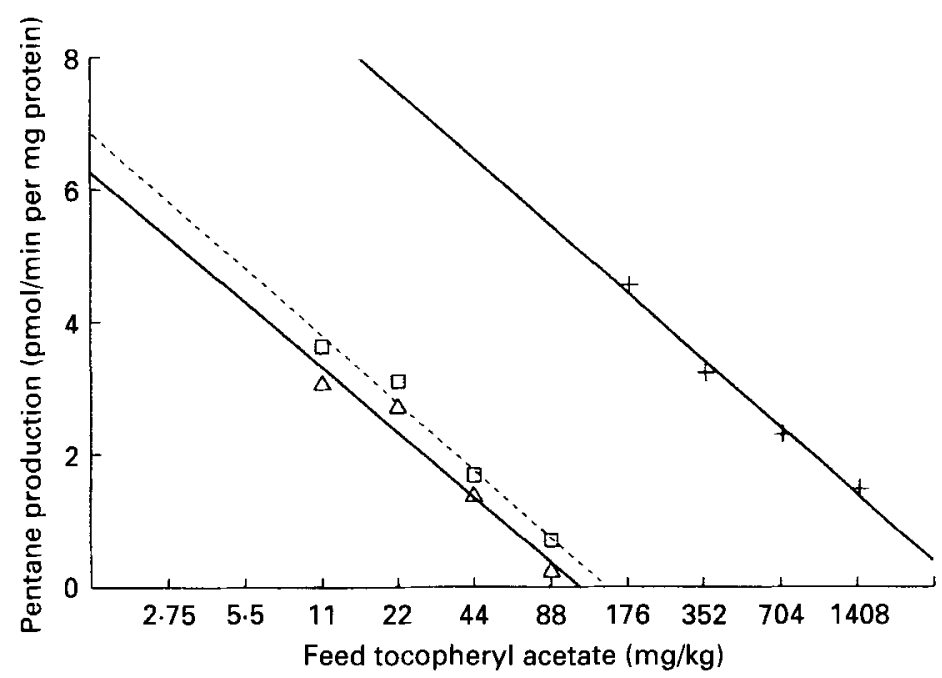

Fig. 3. Pentane production by liver microsomes after 2 weeks of feeding all-rac- $\alpha$-TA $(\square)$, RRR- $\alpha$-TA $(\triangle)$ and $\mathrm{D}-\delta$-TA $(+)$. Each point represents the mean of six to seven chicks.

than the former even when high dosages were applied in the feed. The amount of pentane produced was higher at 21 than at $14 \mathrm{~d}$ of age and differed between the two experiments. The reason for this is not yet known, but it could be speculated that the age difference was accompanied by quantitative and qualitative changes of fatty acids in the microsomes (Budowski et al. 1987) favouring the presence of more $n-6$ fatty acids and thus more pentane production.

Blood, and especially the erythrocytes, may reflect the lability of the whole animal to oxidative conditions (Fraga et al. 1990). The erythrocytes are the major targets of oxy radical attack because they are rich in polyunsaturated fatty acids and are continuously exposed to high oxygen tension. In addition, haemoglobin and the iron it contains are 


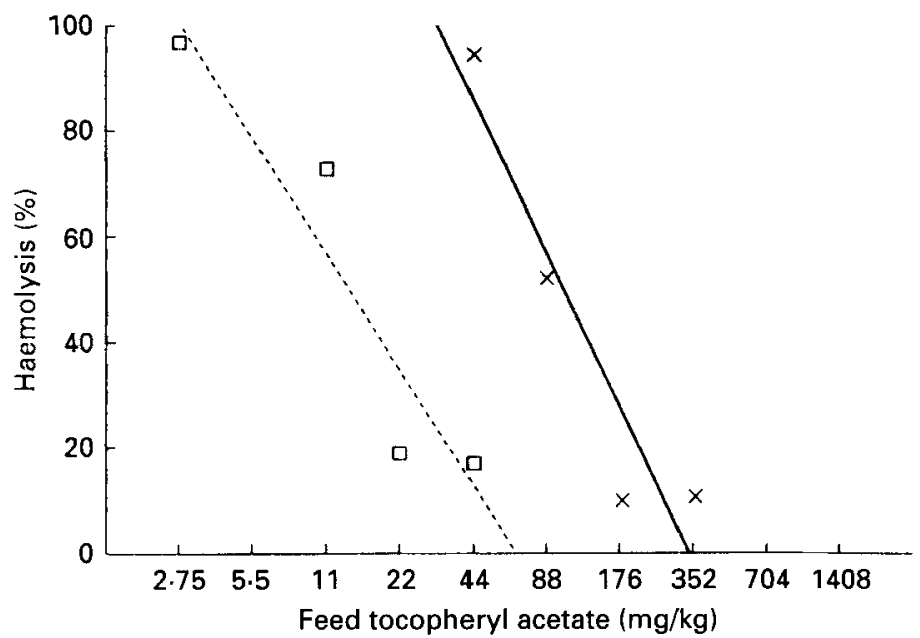

Fig. 4. Haemolysis $(\%)$ after 2 weeks of feeding all-rac- $\alpha$-TA $(\square)$ and D- $\gamma$-TA $(\times)$. Each point represents the mean of six to seven chicks.

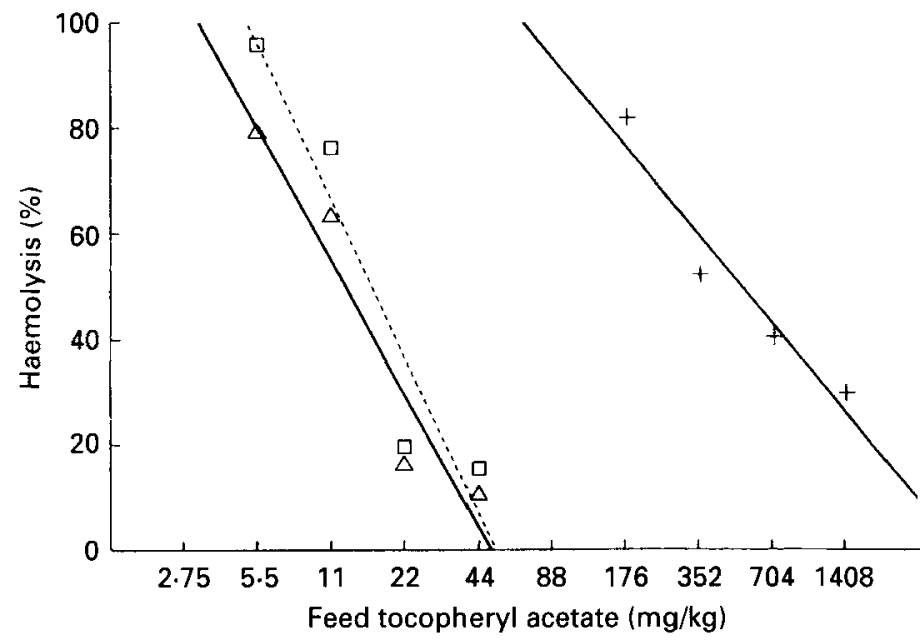

Fig. 5. Haemolysis (\%) after 2 weeks of feeding all-rac- $\alpha$-TA $(\square)$, RRR- $\alpha$-TA $(\triangle)$ and D- $\delta$-TA ( + ). Each point represents the mean of six to seven chicks.

powerful catalysts of oxidative reactions. Insufficient intake of tocopherols leads to oxidative damage of membrane fatty acids of the erythrocyte membrane (Hamada et al. 1982). The non-invasive haemolysis bioassay is an intermediate between those based on biological functions and those involving measurements of tocopherol retention in plasma and tissues (Azaz et al. 1981). Inadequate provision of dietary tocopherols for 2 weeks was accompanied by a high degree of haemolysis (Figs. 4 and 5; results for 3 weeks not shown). This was substantiated by the groups of chickens given $5.5 \mathrm{mg}$ or less of either RRR- $\alpha$-TA, all-rac- $\alpha-\mathrm{TA}, 44 \mathrm{mg}$ D- $\gamma-\mathrm{TA} / \mathrm{kg}$ or $176 \mathrm{mg} \mathrm{D}-\delta-\mathrm{TA} / \mathrm{kg}$ which exhibited complete haemolysis. The natural RRR- $\alpha$-TA was more effective in protecting the erythrocyte membrane against haemolysis than the synthetic all-rac- $\alpha-\mathrm{TA}$, followed by D- $\gamma$-TA and D- $\delta$-TA. 
Table 4. The relative biopotency of tocopherols (all-rac- $\alpha-T A=100 \%$ ) according to microsomal pentane production*

\begin{tabular}{|c|c|c|c|}
\hline Tocopherol & $\begin{array}{l}\text { Common } \\
\text { slope }\end{array}$ & $\begin{array}{c}\text { Relative } \\
\text { biopotency }(\%)\end{array}$ & $\begin{array}{l}95 \% \text { confidence } \\
\text { limit }(\%)\end{array}$ \\
\hline $\begin{array}{c}\mathrm{D}-\gamma \text {-TA } \\
14 \mathrm{~d} \\
21 \mathrm{~d}\end{array}$ & $\begin{array}{l}-4 \cdot 8 \\
-8 \cdot 1\end{array}$ & $\begin{array}{l}18.2 \\
15.8\end{array}$ & $\begin{array}{l}12 \cdot 7-25 \cdot 5 \\
11 \cdot 6-20 \cdot 8\end{array}$ \\
\hline $\begin{array}{c}\text { RRR- } \alpha-T A \\
14 \mathrm{~d} \\
21 \mathrm{~d}\end{array}$ & $\begin{array}{l}-3 \cdot 3 \\
-3 \cdot 8\end{array}$ & $\begin{array}{l}134 \cdot 1 \\
136.7\end{array}$ & $\begin{array}{r}97 \cdot 2-189 \cdot 8 \\
104 \cdot 9-181 \cdot 3\end{array}$ \\
\hline $\begin{array}{c}\mathrm{D}-\delta \text {-TA } \\
14 \mathrm{~d} \\
21 \mathrm{~d}\end{array}$ & $\begin{array}{l}-3 \cdot 3 \\
-3 \cdot 8\end{array}$ & $\begin{array}{l}4 \cdot 1 \\
4 \cdot 2\end{array}$ & $\begin{array}{l}2 \cdot 7-5 \cdot 9 \\
2 \cdot 8-6 \cdot 1\end{array}$ \\
\hline
\end{tabular}

* For details of procedures, see pp. 606-608.

Table 5. The relative biopotency of tocopherols (all-rac- $\alpha-T A=100 \%)$ according to haemolysis*

\begin{tabular}{|c|c|c|c|}
\hline Tocopherol & $\begin{array}{l}\text { Common } \\
\text { slope }\end{array}$ & $\begin{array}{c}\text { Relative } \\
\text { biopotency }(\%)\end{array}$ & $\begin{array}{c}95 \% \text { confidence } \\
\text { limit }(\%)\end{array}$ \\
\hline $\begin{array}{c}\text { RRR } \alpha \text {-TA } \\
14 \mathrm{~d} \\
21 \mathrm{~d}\end{array}$ & $\begin{array}{l}-89.8 \\
-88.8\end{array}$ & $\begin{array}{l}127.1 \\
131.0\end{array}$ & $\begin{array}{l}108 \cdot 8-149 \cdot 1 \\
111 \cdot 6-154 \cdot 7\end{array}$ \\
\hline $\begin{array}{c}\mathrm{D}-\gamma-\mathrm{TA} \\
14 \mathrm{~d} \\
21 \mathrm{~d}\end{array}$ & $\begin{array}{l}-76 \cdot 8 \\
-72 \cdot 1\end{array}$ & $\begin{array}{r}13.8 \\
8.7\end{array}$ & $\begin{array}{c}10 \cdot 2-18 \cdot 8 \\
6 \cdot 7-8 \cdot 9\end{array}$ \\
\hline
\end{tabular}

* For details of procedures, see pp. 606-608.

With the parallel-line assay of the pentane data (Table 4) the bioefficiency of RRR- $\alpha$-TA relative to all-rac- $\alpha$-TA was found to range from 134 to $137 \%$, that for $\mathrm{D}-\gamma$-TA varied from 15.8 to $18.2 \%$. D- $\delta$-TA had the lowest bioefficiency (4\%) using the pentane method. This is an overestimation, because the tocopherol preparation contained a substantial amount of $\alpha$-TA.

The applicability of the parallel-line assay for evaluation of the data requires that the residual variance for the subgroups of data should be constant. This was not the case for the haemolysis data from the groups low or deficient in tocopherol. Therefore, they were excluded from the assay where possible. The haemolysis test (Table 5) gave values of 127 and $131 \%$ for RRR- $\alpha$-TA relative to all-rac- $\alpha$-TA. D- $\gamma$-TA provided lower figures which ranged from 8.7 to $13 \%$. The haemolysis data for D- $\delta$-TA were not used, because the test for parallelism of the regression lines failed.

It should be noted that the estimates of the relative potency for the different tocopherols will only be applicable in the range of responses (Table 1) over which straight lines are a reasonable approximation of the underlying response curves. Therefore, direct comparison between the same doses of all-rac- $\alpha$-TA and D- $\gamma$-TA as well as D- $\delta$-TA is impossible because of their extremely different bioefficiencies.

The inclusion of the complete haemolysis data when calculating the $\mathrm{ED}_{50}$ of the different tocopherols gave nearly identical results for the biopotency (Table 6). Equi-distancy of the 
Table 6. Calculated log effective dose for $50 \%$ reduction of haemolysis $\log E D_{50}$ of the different tocopherols and their estimated relative biopotencies

\begin{tabular}{|c|c|c|c|c|c|c|}
\hline & \multicolumn{3}{|c|}{$2 \mathrm{wk}$} & \multicolumn{3}{|c|}{$3 \mathrm{wk}$} \\
\hline & $\log E D_{50}$ & $\mathrm{CV}$ & $\begin{array}{c}\text { Relative } \\
\text { biopotency (\%) }\end{array}$ & $\log E D_{50}$ & $\mathrm{CV}$ & $\begin{array}{c}\text { Relative } \\
\text { biopotency }(\%)\end{array}$ \\
\hline \multicolumn{7}{|l|}{ Expt 1} \\
\hline All-rac- $\alpha$-TA & $1 \cdot 106$ & $4 \cdot 6$ & 100 & $1 \cdot 151$ & 0.9 & 100 \\
\hline D- $\gamma-$ TA & 1.939 & $2 \cdot 5$ & 15 & 1.968 & $3 \cdot 1$ & 15 \\
\hline \multicolumn{7}{|l|}{ Expt 2} \\
\hline All-rac- $\alpha$-TA & $1 \cdot 127$ & $2 \cdot 7$ & 100 & $1-150$ & 1.5 & 100 \\
\hline RRR- $\alpha$-TA & 1.009 & 5.8 & 131 & $1 \cdot 065$ & $4 \cdot 1$ & 122 \\
\hline $\mathrm{D}-\delta-\mathrm{TA}$ & $2 \cdot 437$ & 1.5 & 5 & $2 \cdot 484$ & $3 \cdot 0$ & 5 \\
\hline
\end{tabular}

$\mathrm{CV}$, coefficient of variation.

* For details of procedures, see pp. 608-609.

curves was not tested, therefore the estimates of the relative biopotency by this procedure are only valid at $50 \%$ reduction of haemolysis.

Most of the published reports on bioefficiency were acquired from rat experiments and were always limited to only two tocopherols. By employing the ex vivo haemolysis test, Friedman et al. (1958) obtained a value of $147.4 \%$ for the bioefficiency of RRR- $\alpha$-TA relative to all-rac- $\alpha$-TA using rat erythrocytes. He recorded a value of $18.9 \%$ for RRR- $\gamma$ TA using the same method. The results obtained in the present study agree to a large degree with the findings of other investigators who nevertheless used different assay tests. Using the pentane exhalation test in rats, Dillard et al. (1983) obtained a value of $31 \%$ for D- $\gamma$-T relative to RRR- $\alpha-T$. Assuming that all-rac- $\alpha-T A$ was the reference tocopherol a figure of $41 \%$ is recorded, which is higher than the one found in this study. Results from the rat resorption-gestation test, which is one of the more common tests, gave values for bioefficiency of RRR- $\alpha-\mathrm{T}$ and $\mathrm{D}-\gamma-\mathrm{T}$ very similar to the present findings (Leth \& Sondergaard, 1977; Weiser \& Vecchi, 1981). Machlin et al. (1982), Chen \& Thacker (1985) and Weiser et al. (1985), using pyruvate kinase $(E C 2.7 .1 .40)$ in rats, obtained a bioefficiency of between 131 and $145 \%$.

Previous findings obtained from chickens and using comparable methods are scanty. Scott \& Desai (1964) used the model of the muscular dystrophic chicken and observed a biopotency of $146 \%$ for RRR- $\alpha$-TA. Dam \& Sondergaard (1964) compared the effectiveness of the different $\alpha$-TA in prevention of encephalomalacia resulting in the somewhat higher bioefficiency of $168 \%$. In the chick liver storage bioassay, Matterson \& Pudelkiewicz (1974) reported a bioefficiency of $121 \%$ for RRR- $\alpha$-TA. The change in creatine kinase $(E C 2 \cdot 7 \cdot 3 \cdot 2)$ under different tocopherol supplementation of chicken feed (Bieri \& Poukka, 1974b) gave a value of $14 \%$ for D- $\gamma$-TA relative to all-rac- $\alpha$-TA; prevention of exudative diathesis resulted in $12 \%$ bioefficiency. These figures indeed support the present findings.

S. T. Balthazary was supported by a grant from DAAD. The authors acknowledge the skilful technical assistance of Mr U. Glockenthoer. Tocopheryl acetates and the reesterified triacyglycerol were generously supplied by Henkel Corp., Duesseldorf, Germany. Rovimix 428 without vitamin $\mathrm{E}$ was a liberal gift of Hoffmann-La Roche, Basle, Switzerland. 


\section{REFERENCES}

Azaz, E., Segal, R. \& Milo-Goldzweig, I. (1981). Haemolysis caused by polyoxyethylene-derivative surfactants. Evidence for peroxide participation. Biochimica Biophysica Acta 646, 444449.

Bieri, J. G. \& Poukka, R. E. (1974a). Vitamin E activity of $\gamma$-tocopherol in the rat, chick and hamster. Journal of Nutrition 104, 850-857.

Bieri, J. G. \& Poukka, R. E. (1974b). Gamma tocopherol. Metabolism, biological activity and significance in human vitamin E nutrition. American Journal of Clinical Nutrition 27, 980-986.

Budowski, P., Leighfield, M. J. \& Crawford, M. A. (1987). Nutritional encephalomalacia in the chick: an exposure of the vulnerable period for cerebellar development and the possible need for both $w 6-$ and $w 3$-fatty acids. British Journal of Nutrition 58, 511-520.

Chen, L. H. \& Thacker, R. R. (1985). Relative biopotency of vitamin E compounds as determined by reversal of plasma pyruvate kinase activity in curative myopathy in rats. Nutrition Research 5, 431-434.

Dam, H. \& Sondergaard, E. (1964). Comparison of the activities of the acetates of d-, dl-, and 1- $\alpha$-tocopherols against encephalomalacia in chicks. Journal of Nutritional Sciences 5, 73-79.

Dillard, C. J., Gavino, V. C. \& Tappel, A. L. (1983). Relative antioxidant effectiveness of $\alpha$-tocopherol and $\gamma$ tocopherol in iron-loaded rats. Journal of Nutrition 113, 2266-2273.

Drapper, H. H. \& Csallary, A. S. (1969). A simplified haemolysis test for vitamin E deficiency. Journal of Nutrition 98, 390-394.

Fraga, C. G., Tappel, A. L, Brian, B. E., Leibovitz, E., Kuypers, F., Chiu, D., Lacono, J. M. \& Kelley, D. S. (1990). Lability of red blood cell membranes to lipid peroxidation. Application to humans fed polyunsaturated lipids. Lipids 25, 111-113.

Friedman, L. W., Weiss, F., Wherry, F. \& Kline, L. O. (1958). Bioassay of vitamin E by dialuric acid method. Journal of Nutrition 65, 143-160.

Gavino, V. C., Dillard, C. J. \& Tappel, A. L. (1984). Release of ethane and pentane from rat tissue slices: effect of vitamin E, halogenated hydrocarbons and iron overload. Archives of Biochemistry and Biophysics 233 , $741-747$

Hafeman, D. G. \& Hoekstra, W. G. (1977). Lipid peroxidation in-vivo during vitamin E and selenium deficiency in the rat as monitored by ethane evolution. Journal of Nutrition 107, 666-672.

Hamada, T., Furuya, M. \& Hodate, K. (1982). Protective effects of vitamin E and dithiothreitol against the hemolysis of rat and goat erythrocytes induced by Tween 20 with or without ascorbic acid and azide. Experientia 38, 462-467.

Hamada, T. \& Matsumoto, M. (1980). The role of vitamin E in preventing the haemolysis of kid and chick erythrocytes with Tween 20. Experientia 36, 978-979.

Herschberger, L. A. \& Tappel, A. L. (1982). Effects of vitamin E on pentane exhalation by rats treated with methyl ethyl ketone peroxide. Lipids 17, 686-691.

Leth, T. \& Sondergaard, E. (1977). Biological activity of all-rac- $\alpha$-tocopherol and RRR- $\alpha$-tocopherol determined by three different bioassays. Nutritional Research 53, 297-331.

Lowry, O. H., Rosebrough, N. J., Farr, A. L. \& Randall, R. J. (1951). Protein measurement with the folin phenol reagent. Journal of Biological Chemistry 193, 265-275.

Machlin, L. J., Gabriel, E. \& Brin, M. (1982). Biopotency of $\alpha$-tocopherols as determined by curative myopathy in the rat. Journal of Nutrition 112, 1437-1441.

Matterson, L. \& Pudelkiewicz, W. J. (1974). Relative potency of several forms of $\alpha$-tocopherol in the chick liver storage bioassay. Journal of Nutrition 104, 79-83.

Rose, S. C. \& György, P. (1952). Specificity of hemolytic reaction in vitamin E-deficient erythrocytes. American Journal of Physiology 168, 414420.

Sallmann, H. P., Fuhrmann, H., Molnar, S. \& Stegmanns, T. (1991). Endogenous lipid peroxidation in broiler chickens under dietary loads. Fat Science and Technology 93, 457-462.

Scott, M. L. \& Desai, D. I. (1964). The relative anti-muscular dystrophy activity of the D and L epimers of $\alpha$ tocopherol and of other tocopherols in the chicks. Journal of Nutrition 83, 39-43.

Tallarida, J. R. \& Murray, R. B. (1987). Manual of Pharmacological Calculations with Computer Programs, 2nd ed. Heidelberg: Springer.

Tien, M. \& Aust, S. D. (1982). Rabbit liver microsomal lipid peroxidation. The effect of lipid on the rate of peroxidation. Biochimica et Biophysica Acta 712, 1-9.

Weiser, H. \& Vecchi, M. (1981). Stereoisomers of $\alpha$-tocopheryl acetate : characterization of samples by physicochemical methods and determination of biological activities in the rat resorption-gestation test. International Journal for Vitamin and Nutrition Research 51, 100-112.

Weiser, H., Vecchi, M. \& Schlader, M. (1985). Stereoisomers of $\alpha$-tocopheryl acetate. III. Simultaneous determination of resorption-gestation and myopathy in rats as means of evaluating biopotency ratios of allrac- and RRR- $\alpha$-tocopheryl acetate. International Journal for Vitamin and Nutrition Research 55, 149-158. 